\title{
Many Southwest Hospitals Will Receive Decreased CMS Reimbursement
}

More hospitals are receiving penalties than bonuses in the second year of the Centers for Medicare and Medicaid Services' (CMS) quality incentive program, and the average penalty is steeper than last year according to a report from Jordan Rau in Kaiser Health News (1). Southwest hospitals reflect that trend with New Mexico and Arizona exceeding the US average both in percentage of hospitals receiving penalties and the average size of the penalty (Table 1). Colorado approximated the national averages (Table 1).

Table 1. Hospital CMS reimbursement bonus/penalty 2014. (For individual hospitals see Appendixes for Arizona, $\underline{\text { Colorado, New Mexico, and the Mayo }}$ Clinic Minnesota).

\begin{tabular}{|l|c|c|c|}
\hline State & $\begin{array}{c}\% \text { Receiving } \\
\text { Bonus }\end{array}$ & $\begin{array}{c}\text { \% Receiving } \\
\text { Penalty }\end{array}$ & $\begin{array}{c}\text { Average of Net } \\
\text { Bonuses and } \\
\text { Penalties }\end{array}$ \\
\hline Arizona & $31 \%$ & $69 \%$ & $-0.12 \%$ \\
\hline Colorado & $51 \%$ & $49 \%$ & $-0.02 \%$ \\
\hline New Mexico & $14 \%$ & $86 \%$ & $-0.31 \%$ \\
\hline U.S. Average & $\mathbf{4 5 \%}$ & $\mathbf{5 3 \%}$ & $\mathbf{- 0 . 0 3 \%}$ \\
\hline
\end{tabular}

Most hospitals are gaining or losing $<0.2 \%$ but in some instances the penalties are substantial. Gallup Indian Medical Center in New Mexico, a federal government hospital on the border of the Navajo Reservation, will be paid 1.14 percent less for each patient and New Mexico's average of a $-0.31 \%$ decline in reimbursement are the largest changes nationally.

"This program is driving what we want in health care," said Dr. Patrick Conway, CMS' chief medical officer. He said most hospitals have improved since the program began a year ago despite more hospitals receiving penalties than bonuses. However, even some hospitals that have gotten better are still losing money because they are not scoring as well as others or have not improved as much.

Most winners from last year stayed winners and losers stayed losers, but there were some switches. For example, Banner Boswell Medical Center in Sun City will receive a $0.36 \%$ bonus in place of a $-0.58 \%$ penalty last year. In contrast, the University of Colorado will receive a $-0.35 \%$ penalty this year compared to a bonus of $0.29 \%$ last year.

This year $45 \%$ of a hospital's change in CMS reimbursement is based process of care measures. Patient satisfaction accounts for $30 \%$. However, for the first time 
$25 \%$ of the score is based on standardized mortality for myocardial infarction, heart failure and pneumonia. CMS is planning to add new measures next year, including comparisons of charges at different hospitals and rates of medical mishaps and infections from catheters.

The maximum readmission penalties grow to $3 \%$ next year and CMS is launching a third incentive program that takes an additional 1 percent of payments away from hospitals with the most patients who suffered injury or infection during their stay. Combined, these measures have the potential to strip away as much as 5.5 percent of CMS payments from the worst performing hospitals starting next October.

As reported in the Southwest Journal of Pulmonary and Critical Care Southwest hospital charges to CMS vary widely for pulmonary and critical care DRGs (2). Also, the complications chosen by CMS do not correlate with outcomes (3). Felton et al. (4) reported higher patient satisfaction was associated with higher admission rates to the hospital, higher overall health care expenditures, and increased mortality and not the expected improvements in outcomes.

Ashish Jha (5) from the Harvard School of Public health examined the latest CMS reimbursement data and reported in his blog that hospitals in the West receiving larger penalties than other areas. Most disturbingly, public hospitals and safety-net hospitals also tended to do worse. As Jha points out these penalties are not large but the change may be relevant for a safety-net hospital operating on a small financial margin.

Richard A. Robbins, MD

\section{References}

1. Rau J. Nearly 1,500 hospitals penalized under Medicare program rating quality. Available at:

http://www.kaiserhealthnews.org/stories/2013/november/14/value-basedpurchasing-medicare.aspx (accessed 11/19/13).

2. Robbins RA. Variation in southwestern hospital charges for pulmonary and critical care DRGs. Southwestern J Pulm Crit Care. 2013;7(1):31-7. [CrossRef]

3. Robbins RA, Gerkin RD. Comparisons between Medicare mortality, morbidity, readmission and complications. Southwest J Pulm Crit Care. 2013;6(6):27886.

4. Fenton JJ, Jerant AF, Bertakis KD, Franks P. The cost of satisfaction: a national study of patient satisfaction, health care utilization, expenditures, and mortality. Arch Intern Med 2012;172:405-11. [CrossRef][PubMed]

5. Jha AK. An update on value-based purchasing: year 2. Available at: https://blogs.sph.harvard.edu/ashish-jha/ (accessed 11/19/13). 